\title{
Left Bundle Branch Block Secondary to Subarachnoid Hemorrhage
}

\author{
Muhammet Gokhan Turtay (iD, Eren Yigit (iD), Sukru Gurbuz (D), Mehmet Ediz Sarihan (D), Hakan Oguzturk (D), Nur Turkmen (iD \\ Department of Emergency Medicine, Inonu University, Malatya, Turkey
}

Cite this article as: Turtay MG, Yigit E, Gurbuz S, Sarihan ME, Oguzturk H, Turkmen N. Left bundle branch block secondary to subarachnoid hemorrhage. Eurasian J Emerg Med. 2018; 17 (3): 141-2.

\begin{abstract}
Many electrocardiogram changes associated with subarachnoid hemorrhage have been described. A 55-year-old female patient was admitted to the emergency service due to complaints of dizziness and fainting after headache persisting for several days. Left bundle branch block was detected on electrocardiogram, and a subarachnoid hemorrhage was detected on brain tomography. Our case illustrates that left bundle branch block may occur in patients with subarachnoid hemorrhage, having no symptoms of a heart problem, previously.
\end{abstract}

Keywords: Left bundle branch block, subarachnoid hemorrhage, electrocardiogram

\section{Introduction}

Several electrocardiogram (ECG) changes associated with subarachnoid hemorrhage have been described (1-6). In the current case report, we present a patient who was diagnosed with subarachnoid hemorrhage and had left bundle branch block (LBBB).

\section{Case Presentation}

A 55-year-old female patient was admitted to the emergency service due to complaints of dizziness and fainting after headache persisting for several days. There were no additional complaints such as chest pain or palpitation. The patient did not have any known history of diabetes, hypertension, heart disease, and other illnesses. Physical examination revealed that the patient was conscious, cooperated, and oriented, and her vital findings were stable. The results of systemic and neurological examinations were normal. The requested blood tests were normal, except hemoglobin: $12.3 \mathrm{~g} / \mathrm{dL}$, hematocrit: $36.3 \%$, and glucose: $162 \mathrm{mg} / \mathrm{dL}$. LBBB was detected on ECG. The results of cardiac enzyme tests were normal. Chest X-ray was normal, but subarachnoid hemorrhage was detected on brain computed tomography (Figure 1). The control ECG taken later was normal, and no LBBB was observed. Subsequently, ECG and cardiac enzyme tests were conducted for the patient at follow-up. In these follow-ups, it was observed that episodic LBBB (Figure 2). No elevation in the levels of cardiac enzymes was observed. The patient was then admitted to the brain surgery intensive care unit. The general condition of the patient began to deteriorate. The patient underwent cerebral angiography and a lobule-irregular contouring saccular aneurysm of the size of approximately 4-5 mm was detected in the right vertebral artery at the level of the posterior inferior cerebellar artery orifice; then the patient underwent endovascular aneurysm embolization. The patient was followed up for 14 days in the intensive care unit. However, the patient's condition worsened, and she died.

\section{Discussion}

Non-traumatic subarachnoid hemorrhages are very important owing to their high mortality and morbidity, although they are not frequent causes of urgent hospital admissions. Many cardiac arrhythmias are

ORCID IDs of all authors: M.G.T. 0000-0002-6213-3963; E.Y. 0000-0002-7881-4616; S.G.0000-0003-2616-0304; M.E.S.0000-0002-2744159X; H.O.: 0000-0002-9800-1428; N.T.0000-0001-7741-8091.

This study was presented in $4^{\text {th }}$ Intercontinental Emergency Medicine Congress, Antalya/Turkey (18-21 May 2017).

Corresponding Author: Muhammet Gokhan Turtay e-mail: mgturtay@gmail.com 


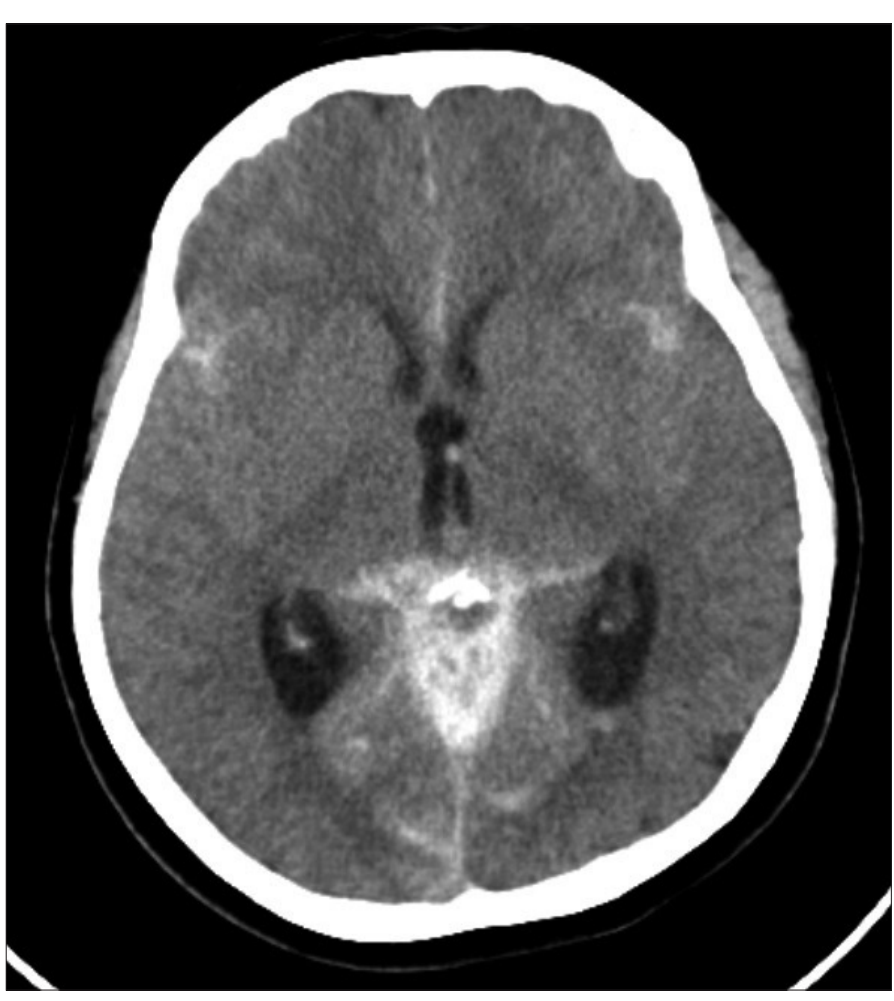

Figure 1. Subarachnoid hemorrhage

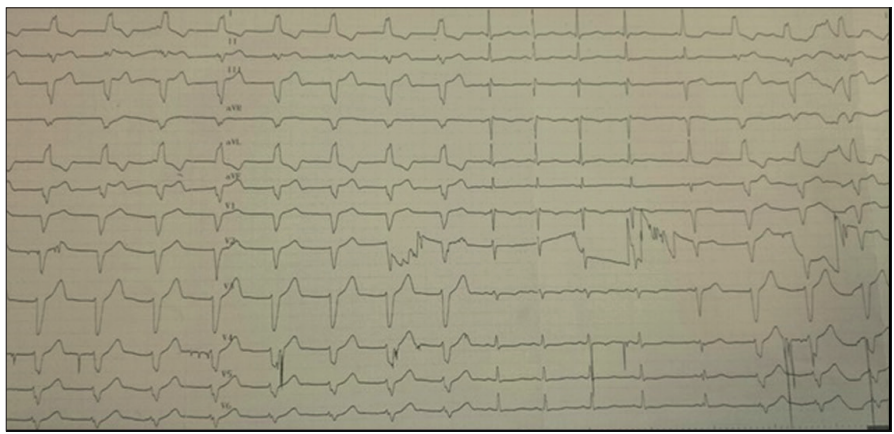

Figure 2. Episodic left bundle branch block

known to develop in patients with subarachnoid hemorrhage (1). LBBB may also develop in patients with subarachnoid hemorrhage (2). The cause of ECG changes in these patients with subarachnoid hemorrhage is not fully understood but appears to have a multi-factorial etiology (2). There is a close relationship between brain and cardiac functions (3). Acute cerebro-vascular disease may lead to cardiac arrhythmias and ECG abnormalities as a result of increased sympathetic nervous system activity and secretion of endogenous catechol amines, causing pulmonary edema and myocardial damage (4). In addition, autonomic dysfunction may contribute to the onset of arrhythmias by disturbing heart rate and blood pressure regulation (5). Clinically significant arrhythmias following subarachnoid hemorrhage have been associated with high mortality (6).
Episodic LBBB is associated with different clinical situations such as bradycardia, tachycardia, anesthesia, acute pulmonary embolism, intrathoracic pressure changes, chest trauma, cardiac interventional procedures, and mad honey poisoning, excluding acute coronary syndrome when the detected episodic LBBB has great prominence. Episodic LBBB and left ventricular systolic and diastolic dysfunction can lead to conduction disorders as well as findings such as syncope (7).

In our case, we investigated other conditions that may be the cause of LBBB in our patient with subarachnoid hemorrhage. The cause of episodic LBBB in our patient was linked to subarachnoid hemorrhage.

\section{Conclusion}

When patients with subarachnoid hemorrhage are diagnosed with $\angle B B B$, the differential diagnosis of the disease that might be the cause of LBBB should be considered. It should be noted that LBBB may occur in patients with subarachnoid hemorrhage and without any cardiac problems.

Peer-review: Externally peer-reviewed.

Author Contributions: Concept - M.G.T.; Design - M.G.T., E.Y.; Supervision - S.G.; Resources - H.O.; Materials - E.Y.; Data Collection and/or Processing M.E.S.; Analysis and/or Interpretation - M.G.T., E.Y., S.G., M.E.S., H.O., N.T.; Literature Search - M.E.S., N.T.; Writing Manuscript - M.G.T.; Critical Review - S.G., M.E.S., H.O.; Other - N.T.

Conflict of Interest: The authors have no conflict of interest to declare.

Financial Disclosure: The authors declared that this study has received no financial support.

\section{References}

1. Andreoli A, di Pasquale G, Pinelli G, Grazi P, Tognetti F, Testa C. Subarachnoid hemorrhage: frequency and severity of cardiac arrhythmias. A survey of 70 cases studied in the acute phase. Stroke. 1987; 18: 558-64. [CrossRef]

2. Dubrey S, Huehns TY, Brooks AP. Subarachnoid haemorrhage: a cause of left bundle branch block? Postgrad Med J. 1994; 70: 578-80. [CrossRef]

3. Keser D, Smajlovic D, Sinanovic O, Serdaroglu P, Grad A, Ajanovic E, et al. Electrocardiographic changes in acute intracerebral hemorrhage. Neurol Croat. 2002; 51: 191-7.

4. Arnaout M, Mongardon N, Deye N, Legriel S, Dumas F, Sauneuf B, et al. Out-of-hospital cardiac arrest from brain cause: epidemiology, clinical features, and outcome in a multicenter cohort*. Crit Care Med. 2015; 43: 453-60. [CrossRef]

5. Soros P, Hachinski V. Cardiovascular and neurological causes of sudden death after ischaemic stroke. Lancet Neurol. 2012; 11: 179-88. [CrossRef]

6. Jeong YS, Kim HD. Clinically significant cardiac arrhythmia in patients with aneurysmal subarachnoid hemorrhage. J Cerebrovasc Endovasc Neurosurg. 2012; 14: 90-4. [CrossRef]

7. Bazoukis G, Tsimos K, Korantzopoulos P. Episodic Left Bundle Branch Block-A Comprehensive Review of the Literature. Ann Noninvasive Electrocardiol. 2016; 21: 117-25. [CrossRef] 